\title{
Thinking Skills in Problem Solving: Pre-Knowledges
}

\section{Ignacio Laiton}

Escuela Tecnológica Instituto Técnico Central, Bogotá, Colombia.

\begin{abstract}
The present article shows the results of a study aimed at evaluating the way in which physics students of first semesters use the thinking skills in problem solving. We speak of pre-knowledge in terms of prior theoretical knowledge of an area of knowledge, in this case it is about identifying pre-knowledge in the case of thinking skills for students who have recently entered higher education. At present, the teaching of thinking skills is considered one of the main characteristics of education for the 21 st century. An instrument of ten problems submitted to expert judgment was designed to be applied during the academic semester to the students of electrical physics of two Colombian universities during the years 2016 and 2018. Are evaluated the categories of description, representation, identification of relationships, use of the mathematical model and drawing conclusions for each of the problems.

The results show statistically a very low starting point in the ability to use such skills, and is in turn a reflection element for the design of effective pedagogical strategies in solving problems in physics in higher education.
\end{abstract}

Keywords: Education; Critical Thinking; Pedagogy; Higher Education. 


\section{Introduction}

The low performance of students in international and national tests in the case of Colombia, as well as the alarming decrease in the number of students accessing engineering careers, are the starting point of the present investigation. The poor academic results of students in areas such as physics and mathematics are reason for the low motivation to access this type of careers, as well as to generate the desertion of the university classrooms.

It is argued that the low capacity to use thinking skills in solving problems in science, which involve an important combination of knowledge, as well as a high level of thinking, is the basis for the problem of low ability to solve problems. Although the need for the use of higher thinking skills in solving problems in science is recognized, the corresponding studies focus more on other aspects of the problem.

Benegas and Villegas (2011) focus, for example on the influence of the type of problems faced by a student of physics, these authors highlight aspects such as the importance of the statement in the context of the resolution of a problem in physics. They focus on the incidence of the statement and its implicit context, differentiating the statements from the end of chapter exercises, versus statements more related to everyday life. They find that the students of the first semesters of the university show poor results when they face statements related to everyday reality, apparently closer to the individual. It should be noted that in this case it focuses more on performance, differentiating the type of end-of-chapter problem from statements of daily life, without taking into account cognitive and thought elements that the student must involve in its solution.

On the other hand, Inzunza and Brincones (2010) carry out a study with students of the University of Alcalá de Henares, where they try to identify the mental processes that students use during the execution of the task of solving physics problems. It is found that the students are not able to make the process explicit, since they tend to be very mechanical, as it seems that they have been previously taught. It is also concluded that students do not develop the complete process taught to solve a problem and tend simply to move towards mathematical calculations. In this case the type of problem situations is directed to problems where it is necessary to use equations to perform mathematical calculations, rather than to analyze them.

Also Guirado, Mazzitelli and Maturano (2013), Guisasola, Ceberio and Zubimendi (2011), Perales (2000), Truyol, Sanjosé and Gangoso (2014) show works related to the resolution of problems, which reiterate from their perspective what is considered one of the main contributions of teaching to the integral formation of the individual. Likewise, Franco,

Almeida and Saíz (2014), Beltrán and Torres (2009), Olivares and Heredia (2012) among others insist on the importance of involving the teaching of critical thinking skills in current 
education. However, in the field of physics it is not where more researches are found, and the great majority is focused on the resolution process, its steps and results, it differs substantially from the present study.

Unlike most previous studies, the possibility of identifying pre-knowledge of physics students of the first semesters of university, with regard to thinking skills acquired in their previous stage of secondary education in Colombia, is proposed here. The information obtained aims to identify the reason why a student does not usually perform adequately in the solution of problems in physics in engineering, since it does not possess the elements of thought necessary for it. present work is then oriented to evaluate the way in which physics students of first semesters use the thinking skills in the solution of problems of electrical physics in engineering.

\section{Methodology}

The present investigation is a mixed investigation (Colas, Buendía \& Hernández, 2009). A first quantitative element focuses on the operationalization of problem solving through a licker scale, monitoring the process itself of the solution of each problem by the student, and developing a descriptive statistical analysis that identifies the marked trends. Secondly, the skills that the student uses or not in the solution of each problem are described and analyzed qualitatively, each element of the process is observed in the search of those elements of analysis and thinking skills used in an adequate way by the student.

The work was developed during five consecutive semesters of teaching of electrical physics, in the classrooms of the Technological School Central Technical Institute of Bogotá and the University of La Salle taking a sample of 120 students from the two institutions. As an instrument for gathering information, a test of ten typical electrical physics problems, extracted from traditional texts and submitted to the judgment of experts, professors of the basic sciences of the participating institutions, was used. the preknowledge are evaluated in the five categories of description of the scenario where the phenomenon is developed (1), graphic representation of the situation (2), precise identification of the relationships between the variables involved (3), logical use of the mathematical process (4), and finally to reach the conclusions of the process (5). Each of the above items was given a value of one if it appeared in the solution presented by the student, and zero if it did not appear in the process. In this way each student has a range of values for their evaluation from zero to fifty. The test was applied at the end of each semester of the fieldwork, when the students had already accessed the theoretical knowledge necessary for the physical solution of the problem, under the classical teaching methodology. 


\section{Results}

It can be seen from the information collected that the students' performance is very low. In table 1, the results and statistical trends are clear and significant in that they reveal the very low level of the second semester students of the participating universities that were submitted to the test. The mean of the sample is only 20.36 on a total score of 50. It was observed that although some students obtained a score above 25 , there were few cases, so that most do not adequately develop the process to solve problems, nor adequately use the thinking skills necessary and implicit in this process, their pre-knowledge in this field can be considered minimal.

Table 1. General description of results

\begin{tabular}{lc}
\hline Average & 20,3571429 \\
Typical error & 1,42815928 \\
Median & 20,5 \\
Mode & 12 \\
Standard deviation & 5,34368272 \\
Variance & 28,5549451 \\
Range & 18 \\
Minimum & 12 \\
Maximum & 30 \\
\hline \multicolumn{2}{c}{ Source: The author $(2018)$} \\
\hline
\end{tabular}

On the other hand, if the score is analyzed by category, (table \# 2) it can be seen that the highest average is that corresponding to the mathematical process, even though it is still a low score. It can be inferred from now on, that the mathematical process is more developed than the analytic process. It is also observed that the lowest score corresponds to the category of the identification of relations between variables. This aspect involves the use of higher order thinking skills.

Table 2: Average Score per Category (120 students)

\begin{tabular}{llllcc}
\hline Category & scenario & graphic & relations & math process & conclusions \\
Average & 3,85 & 4,23 & 3,51 & 5,32 & 3,45 \\
\hline
\end{tabular}

Second, the most relevant aspect was the observation that students tend to go mechanically to the use of equations, without going through the conceptual analysis, the characterization 
of the phenomenon, the theoretical relationships between variables. In this sense, it is further observed that, in most cases, even calculating a numerical data through the equation does not imply developing any degree of analysis and search for meaning, it seems to represent only a hope of having succeeded with a prefixed solution that leads to obtaining a satisfactory rating.

An analysis from the necessary pre-knowledge leads us to consider, in the first place, that the student does not consciously identify the scenario within which the phenomenon is developing, can be terrestrial gravitational field, region in which a magnetic field is present, etc. The student cannot make explicit the conditions imposed by the environment of the phenomenon, even if tacitly recognizes the existence of a phenomenon already predicted by what is discussed in class. Although it identifies the variables involved in the matter, it does so more by the fact that its pre-knowledge guides it towards the fact that it appears in the equation, rather than the fact of observing the consequences in real life. They are not aware, in general, of the consequences involved, neither symmetry and cause-effect issues that would imply similar results in parallel phenomena. He is aware that the equations lead him to a response to certain questions already predesigned, but not with the amplitude of the detailed description of the event, and the possibility of predicting any situation adapted to the parameters of the same.

\section{Conclusions}

The aspect that the best performance of the studied sample barely reaches 30 points over 50 , constitutes proof that the student of first semesters of higher education of engineering careers in Colombia, arrive with very few pre-knowledge needed in the aforementioned to the thinking skills necessary to face challenges such as the solution of problems in physics, the basis for engineering careers, and in turn the basis for the technological development of any country. Very low contextual analysis, low perception of the phenomenon, little analysis of relationships and final consequences of physical laws. It is intuited that the educational process prior to training the student, not to analyze but to find answers, and that most of the evaluation instruments used usually request a number, a data, a specific response, when what should be asked is an analysis, a possibility, a condition. The thinking skills have not been taken into account in the process.

It is concluded that the working hypothesis is true, and that the students do not have the capacity to access the adequate use of their superior thinking skills necessary for the evaluated process. It follows from this that it is necessary to implement methodologies for teaching this type of skills, if you want the level of graduates of engineering careers in Colombia to be enough to face the development challenges of the country, as well as motivate the students and decrease the desertion of the university classrooms in Colombia. 
It is proposed as an idea to involve alternative strategies, such as the so-called routines of thought (Marina, 2012), cognitive modifiability (Feuerstein and Feuerstein, 2010), among others, that invite the student to act in a methodical manner, with clear and concise objectives of learning, methodologies that invite, among others, to turn everyday things into a reason for reflection, aspects that are already so common in our environment, that they are no longer a cause for reflection. Understanding that these strategies are clearly transversal to the different areas of knowledge, with the corresponding implications.

\section{References}

Benegas, Julio. y Villegas, Myriam. (2011). Influencia del Texto y del Contexto en la Resolución de Problemas de Física. LAJPE, Vol. 5, n¹, 217-224.

Beltran, Juliana. y Torres, Nydia. (2009) Caracterización de habilidades de pensamiento crítico en estudiantes de educación media a través del test HCTAES. Zona Próxima, Vol. 11, 66-85.

Colás, P. Buendía L. y Hernández F. (2009). Competencias Científicas para la Elaboración de una Tesis Doctoral. Barcelona: Editorial Davinci.

Feuerstein, Reuven y Feuerstein, Rafael. (2010) Beyond Smarter. Mediated Learning and the Brain's Capacity for Change. New York. Teachers College Press.

Franco, Amanda. Almeida, Leandro y Saiz, Carlos. (2014). Pensamiento crítico: reflexión sobre su lugar en la Enseñanza Superior. Educatio Siglo XXI, Vol. 32, n 2, 81-96.

Guirado, Ana. Mazzitelli, Claudia y Maturano, Carla. (2013). La Resolución de Problemas en la Formación del Profesorado de Ciencias: Análisis de las Opiniones y Estrategias de los Estudiantes. Revista Eureka Sobre Enseñanza y Divulgación de las Ciencias. Vol. 10,número extraordinario, 821- 835.

Guisasola Jenaro. Ceberio Mikel. Almudí José. y Zubimendi José. (2011) La resolución de problemas basada en el desarrollo de investigaciones guiadas en cursos introductorios de Física. Enseñanza de las Ciencias. Vol. 29, n³, 439-452.

Insulsa, Juan. y Brincones, Isabel. (2010). Aprendizaje de la Física por Resolución de Problemas: Caso de Estudio en Alcala de Henares. Theoria, Vol. 19, n², 51-59.

Marina, José. (2012). La Inteligencia Ejecutiva. Barcelona. Editorial Planeta S.A.

Olivares. Silvia. y Heredia. Yolanda. (2012). Desarrollo del pensamiento Crítico en ambientes de aprendizaje basado en problemas en estudiantes de educación superior. Revista Mexicana de Investigación Educativa. Vol. 17, n54, 759-778.

Perales Francisco. (2000) La resolución de problemas, en Perales F. y Cañal, P. (Eds.), Didáctica de las ciencias experimentales (289-306). España: Marfil.

Truyol, María. Sanjosé, Vicente. y Gangoso, Zulma (2014) Obstacles modeling reality: Two Exploratory Studies on Physics Defined and Undefined Problems. Journal of Baltic Science Education, Vol.13, ${ }^{\circ} 6,883-895$. 